\title{
ANTAS NO CAMIÑO. PREHISTORIA E ARQUEOLOXÍA NOS CAMIÑOS XACOBEOS DO NORTE
}

\author{
JUAN A. CARNEIRO REY ${ }^{1}$
}

\begin{abstract}
Resumo
Neste traballo estúdase a Prehistoria recente nas terras polas que transcorre un dos camiños de peregrinación a Santiago de Compostela: o Camiño do Norte. En primeiro lugar analizamos o entorno xeográfico e os restos arqueolóxicos, que conforman unha riqueza cultural que vai dende o Paleolítico ata o mundo romano e a época medieval. A continuación faise unha escolma dos estudos pioneiros levados a cabo nesa zona desde o século XIX. Por último se rexistra a distribución espacial do fenómeno tumular nas dúas áreas máis salientables do itinerario: a Terra Cha e a Terra de Melide. Ao igual que noutros lugares de Galicia e da Península, os túmulos megalíticos están vinculados a antigos camiños e sitúanse en zonas de paso que comunican as terras altas coas baixas.
\end{abstract}

\section{Palabras Clave}

Camiño do Norte a Santiago de Compostela; Fenómeno tumular; Vías de tránsito.

\begin{abstract}
We deal in this paper with the recent prehistoric record to be found along the northern route of the pilgrimage to Santiago de Compostela. To start with, we analyze the physical environment and the archaeological remains that have a wide cultural scope, ranging from the Paleolithic to the Medieval ages. We carry on with a review of the earlier research on this topic, from the XIX century onwards. Lastly, we trace the spatial distribution of the megalithic phenomenon in two of the most outstanding areas from this route, Terra Cha and Terra de Melide where, like in other peninsular zones, funerary mounds are commonly linked to old paths that communicate the highlands with the valleys below.
\end{abstract}

\section{Key Words}

Northern pilgrimage route to Compostella. Megalithic mounds. Natural paths.

\footnotetext{
${ }^{1}$ Departamento de Historia I. Área de Prehistoria. Universidade de Santiago de Compostela.
} 


\section{A PAISAXE}

Os camiños que levan a Compostela e que entran polo norte de Galicia gozan dunha ampla variedade paisaxística².

O Camiño Primitivo entraba desde Asturias pola Fonsagrada atravesando de Leste a Oeste os sistemas montañosos orientais e chegando a Lugo, baixando logo por Guntín ata xuntarse co Camiño Francés en Palas de Rei.

Nas terras da Fonsagrada, a máis de 1.000 metros de altitude, atópase a anta de Hospital, a poucos metros do antigo hospital de peregrinos de Santiago de Montouto, fundado no século XIV. Trátase dun monumento megalítico que conserva en pé catro chantos de preto de dous metros de altura e é un dos máis salientables deste período da Prehistoria recente nesta zona..

$\mathrm{Na}$ veciña Asturias tamén existen importantes conxuntos megalíticos relacionados cos exemplares galegos e do norte de Portugal. Preto de 1.000 túmulos repártense entre a Sierra Plana de la Borbolla (Llanes), Monte Areo, (Carreño) e a Sierra de Carondio (Allande) (de Blas, 1995).

O chamado Camiño do Norte en Galicia parte dende a rasa cantábrica, na Mariña luguesa, e pasa por serras como a de Lourenzá, ou por chairas formadas por depresións tectónicas como a de Vilalba. Máis adiante o Camiño atravesa comarcas limitadas pola Serra da Loba, Cordal de Montouto, Serra da Cova da Serpe (Guitiriz, Baamonde, Sobrado), continuando por superficies de erosión, abas suaves e amplos vales (Arzúa, O Pino), ata chegar a Compostela, situada entre dúas bacías: a do Tambre e a do Ulla, onde se complementan rasgos da Galicia septentrional coa meridional e zonas amesetadas con vales.

Toda esta variedade fisiográfica fai que os Camiños do Norte sexan itinerarios con paisaxes variadas e proclives ao asentamento humano polo que xa eran coñecidos desde tempos moi remotos.

\section{OS RESTOS DO PASADO}

Existen pegadas do Paleolítico Inferior en Vilaselán (Ribadeo); do Paleolítico Superior - Epipaleolítico en Xermade, Vilalba e Abadín (Fábregas, 1996). Así mesmo hai restos de principios da metalurxia: machados de cobre e puntas palmela en

\footnotetext{
${ }^{2} \mathrm{O}$ noso agradecemento a Rosa Méndez e Xosé Leira, coordinadora e director, respectivamente, do Proxecto «Aulas no Camiño» da Facultade de Humanidades de Ferrol. Universidade da Coruña. Sen o seu interés e confianza non sería posible a realización deste traballo.
} 




Figura 1.- Camiños Xacobeos do Norte.

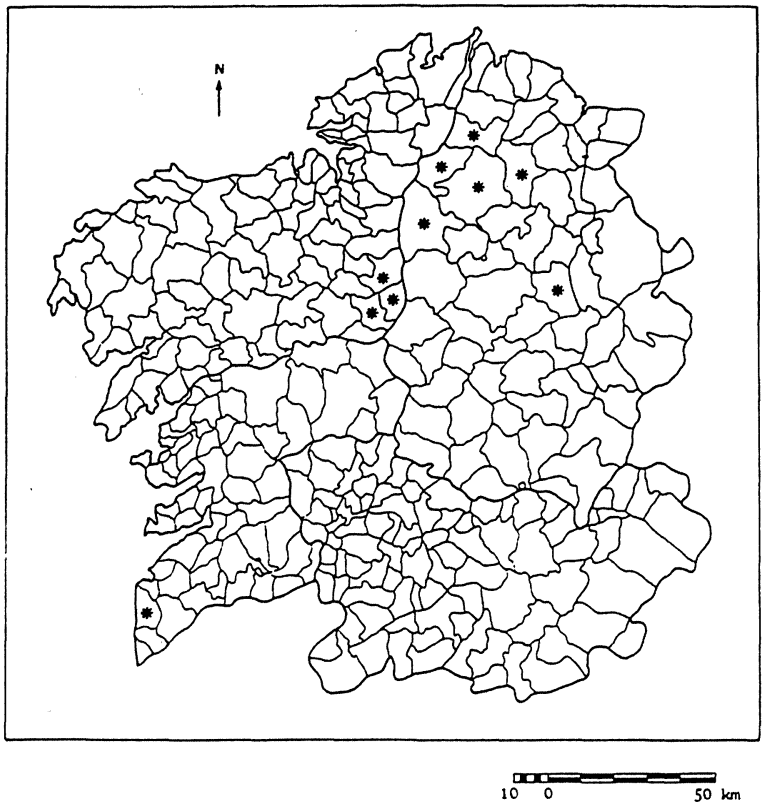

Figura 2.- Xacementos do Paleolítico Superior-Epipaleolítico (Fábregas, 1996).

Cuadernos de Estudios Gallegos, Tomo LII, Fascículo 118, Santiago 2005. (Págs. 199 - 213) 
Vilalba. Mámoas e castros abundantes en Ribadeo, con achados importantísimos: torques e unha diadema de ouro. Arante, cun castro sobre un outeiro. Vilalba con máis de 30 castros e 200 medoñas catalogadas posúe unha importante ergoloxía: machados de pedra, de bronce, coitelos de sílex, puntas de frecha... ademais contaba con importantes mostras artísticas da Idade do Bronce, como petroglifos, desgraciadamente desaparecidos moitos deles. Nesta comarca contamos con algúns establecementos rurais romanos e mostras da súa relixiosidade: unha ara adicada a Mercurio, o deus dos camiños e protector dos camiñantes e viaxeiros. Parga, co barrio chamado do castro e coroado por este, tamén conta coa descuberta dunha ara romana adicada aos Lares Viales, o mesmo que en Guitiriz, divindades relacionadas cos camiños. Arzúa, atravesada por unha vía militar e unha ponte romana sobre o Iso. O Pino, con restos das culturas megalítica, castrexa e romana; con castros nos que se acharon dous torques de ouro de 24 quilates e medio quilo de peso.

Éstes son só algúns exemplos da riqueza cultural do itinerario que desde o Cantábrico chega a Compostela (VV.AA., 1991, 1993).

\section{ESTUDOS PIONEIROS VERBO DA PREHISTORIA RECENTE NOS CAMIÑOS DO NORTE}

Ao igual que no resto de Galicia, os primeiros estudos con vocación científica sobre o fenómeno tumular nas comarcas luguesas e coruñesas polas que discorren os Camiños do Norte están moi espallados en publicacións locais e provinciais.

As primeiras datas de edición de publicacións sobre o megalitismo corresponden a finais do s. XIX e a principios do s. XX. Podemos citar revistas como Galicia Diplomática, o Boletín de la Real Academia Gallega, o Boletín de la Comisión de Monumentos Históricos y Artísticos de Lugo, ou mesmo a revista Nós. Ademais do volume interdisciplinar realizado polo Seminario de Estudos Galegos en 1933: Terra de Melide.

Os autores que escriben sobre esta zona son maioritariamente galegos, pero tamén hai portugueses e incluso alemáns. Son de salientar: Villa-Amil y Castro (1866, 1873, 1878), Bernardo Barreiro (1888), Leite de Vasconcelos (1905), Álvarez Carballido (1907), Amor Meilán (1918), Alfredo Álvarez (1919), López Cuevillas (1927), López Cuevillas e Bouza Brey (1927), G. Leisner (1938)³.

\footnotetext{
${ }^{3}$ Pódese ampliar esta relación en López Cuevillas e Bouza Brey (1927). Máis recentemente publicáronse sínteses sobre a historia da investigación no megalitismo galego en Rodríguez Casal $(1990,1993)$ e desde a perspectiva dos estudios territoriais en Carneiro Rey (1999).
}

Cuadernos de Estudios Gallegos, Tomo LII, Fascículo 118, Santiago 2005. (Págs. 199 - 213) 


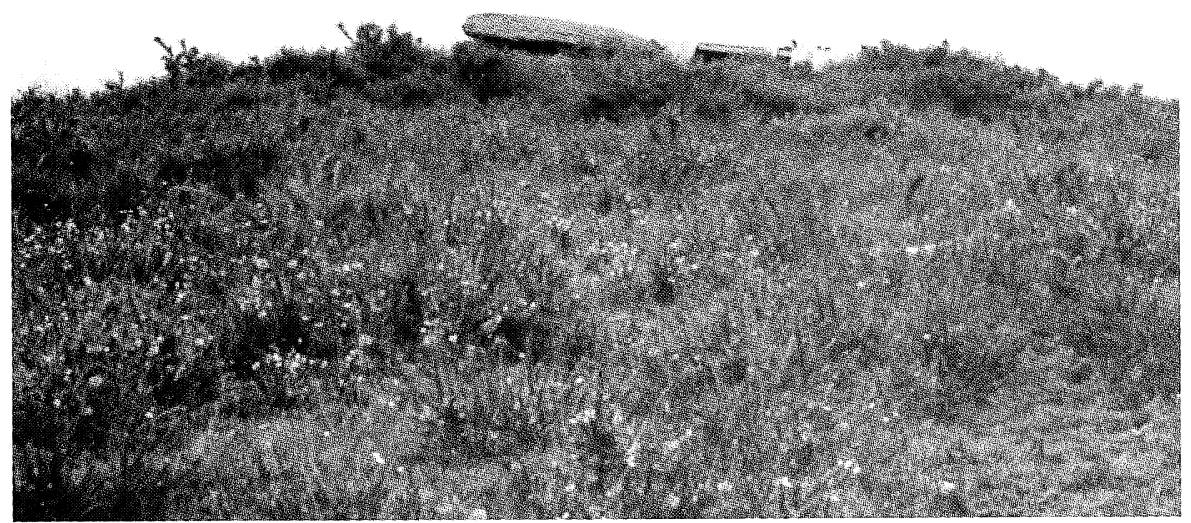

Figura 3.- Túmulo da anta «Forno dos Mouros» (Toques).

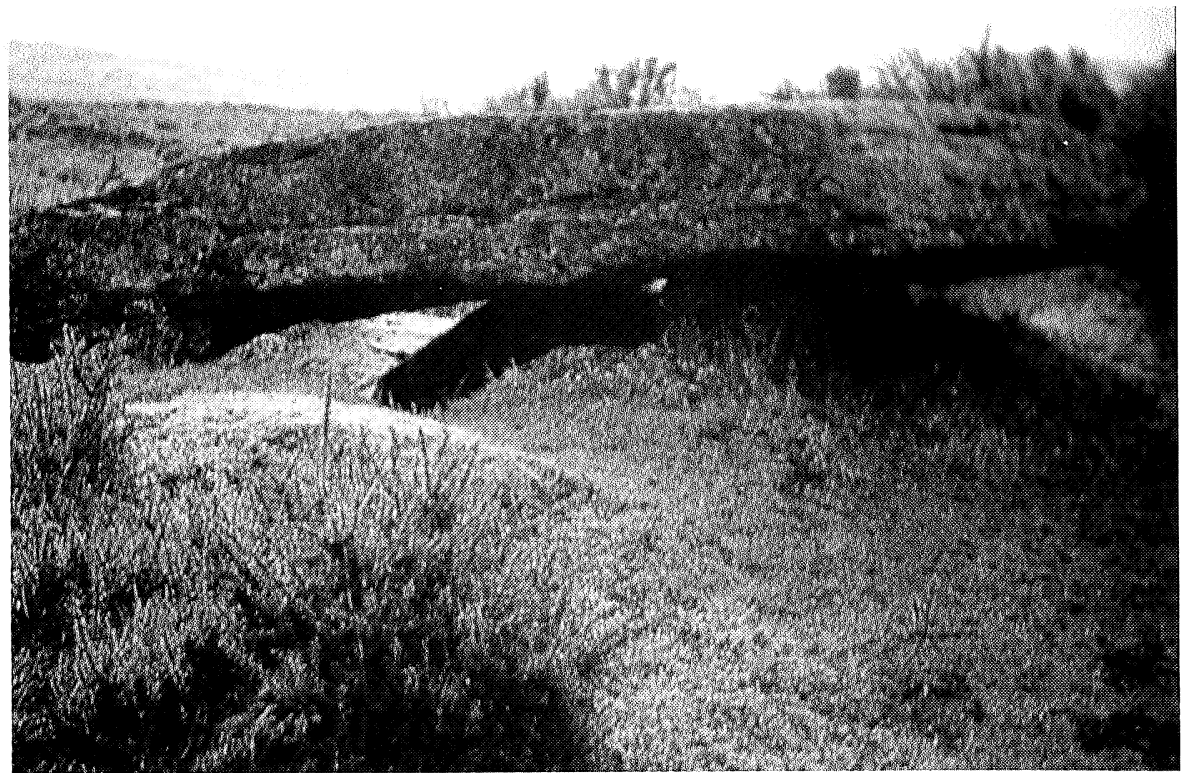

Figura 4.- «Forno dos Mouros» antes da súa escavación.

Cuadernos de Estudios Gallegos, Tomo LII, Fascículo 118, Santiago 2005. (Págs. 199 - 213) 


\section{DISTRIBUCIÓN ESPACIAL DO FENÓMENO TUMULAR}

Existen dúas grandes áreas ou comarcas nas que destaca a proliferación de monumentos tumulares dentro da nosa zona de estudo. En primeiro lugar está a Terra Cha, e en segundo lugar a Terra de Melide.

A Terra Cha: Nos arredores de Vilalba están catalogadas máis de duascentas vinte mámoas (Pombo e Rego, 1992). As necrópoles máis numerosas son a do Carrizo, con 19 túmulos e a de Lousada con 17 túmulos. Interesante é a pedrafita chamada Pedra Chantada, de tres metros de altura. Actualmente ten a función de marco divisorio de parroquias e está preto dunha necrópole tumular. Esta pedra está ateigada de coviñas, as máis delas feitas pola erosión. O seu carácter de monumento prehistórico non está demostrado.

Ergoloxía: Tense atopado unha gran cantidade de útiles líticos: machados e aixolas de lousa. Así como prismas, xeométricos, lascas, follas e puntas de frecha, tanto en sílex como en cristal de rocha, ademais de numerosos anacos de cerámica campaniforme e de tipo Penha.

Arte: Así mesmo apareceron dúas chantas decoradas con coviñas; a denominada Pedra dos Millós e o esteo de Mollafariña $\mathrm{n}^{\circ}$ 2. Na necrópole de Roza das Modias existen esteos con decoración de liñas onduladas paralelas verticais. No Agro das Calzadas (Guitiriz) atopámonos cun petroglifo formado por un gran reticulado enmarcado nos dous extremos con motivos absidados e atravesado por liñas horizontais, ademais está relacionado con motivos circulares e coviñas. A decoración de reticulados aparece en cistas, petroglifos e cámaras dolménicas en todo o occidente peninsular. Trátase dunha representación que se remonta ao Neolítico e que se reinterpretará ao longo das diversas épocas (Fábregas e Penedo, 1994).

Localización: A maior parte das mámoas desta zona están situadas en terras adicadas á roza e máis da metade están emprazadas á beira de antigos camiños. Esta circunstancia dase noutros lugares de Galicia, así como noutras zonas megalíticas peninsulares e europeas. $O$ feito de que moitas necrópoles teñan unha disposición alongada indica que existía unha relación entre o tránsito, tanto na vida como na morte.

O certo é que moitas necrópoles están situadas en zonas estratéxicas de pasos naturais e éstes foron utilizados desde moi antigo e ao longo de tódalas épocas ata chegar á actualidade (Maciñeira, 1943; Bello, Criado e Vázquez, 1982; Vázquez e Pombo, 1995).

Demografía: A partir do número de mámoas e de necrópoles realizáronse uns cálculos hipotéticos verbo da demografía en época megalítica (Vázquez e Pombo, 


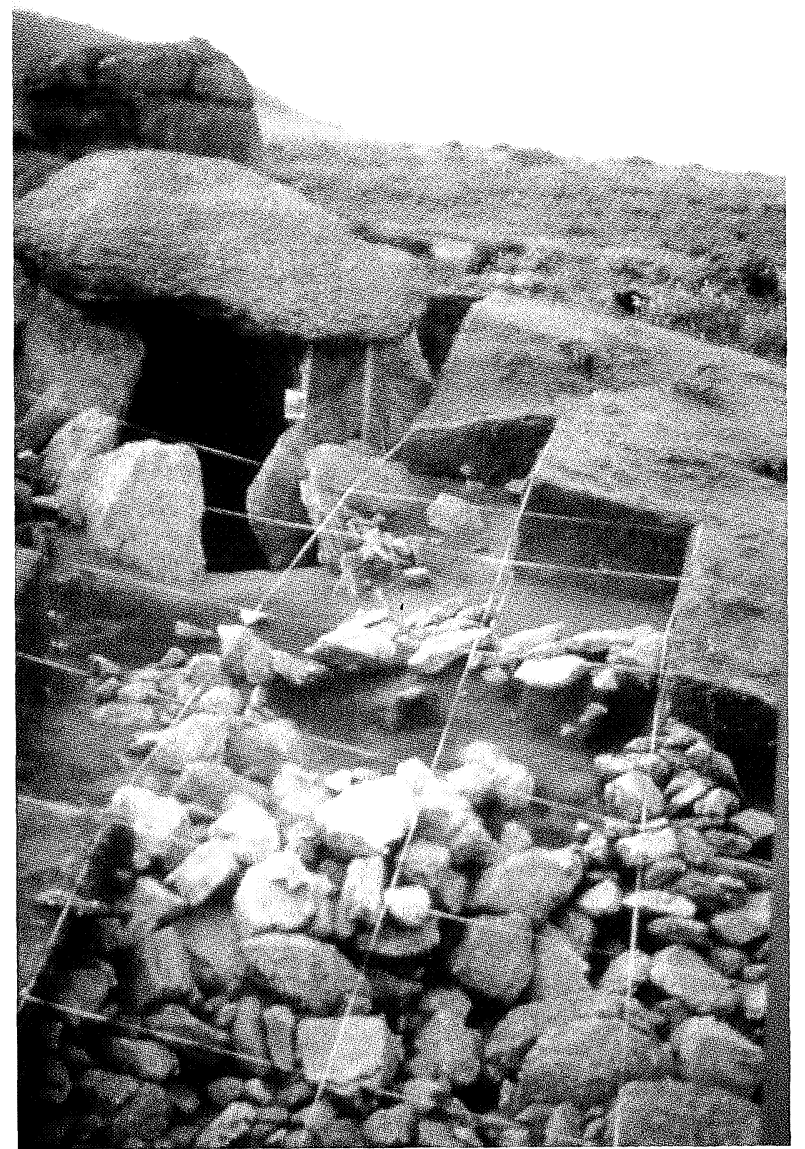

Figura 5.- «Forno dos Mouros» durante a súa escavación (Criado, 1991).

1992). As conclusións deste estudo dan unha media de 1,4 habs. $/ \mathrm{km}^{2}$, do que resulta unha poboación absoluta para esta zona de 716 habitantes. Pola distribución das necrópoles pódese deducir un tipo de sociedade segmentada en pequenas unidades sociais moi dispersas, pero uniformes en canto á cantidade de individuos.

A Terra de Melide: Dentro desta ampla bisbarra salientaremos dúas sub-áreas: a de Sobrado-Vilasantar ao norte, e a de Melide-Toques ao sur.

Na primeira localización hai catalogadas máis de 210 mámoas, situadas en xeral en zona de penechaira (Criado, 1980). As dimensións dos túmulos varían entre os $10 \mathrm{~m}$. e $30 \mathrm{~m}$. de diámetro e entre $0,5 \mathrm{~m}$. e $2,5 \mathrm{~m}$. de altura. 
Na segunda sub-área atópase outra interesante zona megalítica que xa foi investigada desde antigo, catalogándose 74 mámoas (López Cuevillas, 1933). Máis recentemente realizáronse outros traballos arqueolóxicos, destacando un amplo estudo que abranguía un extenso espacio de tempo: desde o Paleolítico ata a Idade Media. O devandito estudo collía á área Bocelo-Furelos, dentro dun proxecto de investigación da Universidade de Santiago dirixido por Criado (1991). Realizáronse tres campañas entre os anos 1987 e 1989.

Tamén no val do Furelos arqueólogos da Universidade de Santiago e da Universidade de Lodz (Polonia) escavaron neses anos o castro da Graña.

Entre as diversas conclusións obtidas no estudio do fenómeno tumular salientan que os materiais do entorno das necrópoles tumulares non condicionan a construcción destas, xa que se utilizan distintos tipos de rocha para a erección das antas. A distancia da zona de extracción de lousas ata o monumento non soe ser moi grande: entre $5 \mathrm{~m}$. e $200 \mathrm{~m}$. Esta circunstancia variará en épocas posteriores, pois foi atopada unha necrópole de cistas nunha zona na que os megalitos están construídos en granito, nembargantes as cistas están realizadas noutro material que se localiza a unha distancia entre $6 \mathrm{Km}$. e $8 \mathrm{Km}$.

A maior parte das mámoas sitúanse nas zonas de solos lixeiros e pouco profundos, alonxadas dos chans pesados e difíciles de traballar coa tecnoloxía da época megalítica (Criado e Grajal, 1981).

Examinando a documentación medieval do mosteiro de Sobrado, así como a moderna (Catastro de Ensenada), púidose apreciar que estas terras non foron moi explotadas para a agricultura e que a destrucción de mámoas non foi moi grande ao longo da historia, sendo esta destrucción máis frecuente na actualidade debido á mecanización agrícola, a apertura de pistas e a concentración parcelaria (Bello, Criado e Vázquez, 1987) .

${ }^{4} \mathrm{O}$ feito de que non foran localizados monumentos megalíticos aludidos na documentación medieval (do mosteiro de Sobrado, neste caso) co nome de «arcas», pódese deber a que esta denominación non se identifica necesariamente coa cámara dolménica dun monumento megalítico, senón que pode ter o significado de simple marco delimitatorio, especialmente relevante, pero máis doadamente eliminable polos avatares históricos que as propias construccións megalíticas tradicionais (Carneiro, 2000). 




Figura 6.- Pedra Chantada (Santaballa, Vilalba).

\section{ANTAS NO CAMIÑo}

Practicamente tódalas mámoas desta zona están vinculadas a camiños antigos. As necrópoles distribúense nun espacio polo que discorre un camiño. Esta asociación, como xa se dixo anteriormente, ven dada polas facilidades de comunicación natural entre áreas xeográficas. Os Camiños Reais fóronse construíndo seguindo as condicións orográficas que permitían o paso e a comunicación, neste caso, entre as provincias da Coruña e Lugo, a través dos montes Campelo e do Bocelo.

Debido a esta circunstancia de trazado viario en zonas óptimas para o paso dentro de áreas con grandes dificultades orográficas, os camiños fóronse superpoñendo uns a outros ao longo da historia por idénticos ou similares trazados (Bello et al. 1982; Criado, Fábregas e Vaquero, 1990-91).

Existe unha mámoa na Terra de Melide que foi escavada en 1983. Trátase da medorra de Fanegas, un túmulo megalítico que foi reaproveitado en época romana como torre de vixilancia, relacionada co cercano campamento de Cidadela (Caamaño e Criado, 1991-92). O túmulo ten $28 \mathrm{~m}$. de diámetro e 2,5 m. de altura. No seu interior había varias lousas de pequeno tamaño tiradas polo paleosolo. A 
mámoa estaba cinguida por unha coiraza irregular. A violación romana consistía nunha construcción rectangular de $7 \times 4 \mathrm{~m}$. cunha función de corpo de garda e control da calzada que se dirixía a Cidadela e que pasa a rentes da medorra. Os materiais constructivos son similares aos utilizados no campamento. A cronoloxía sitúase entre os ss. II-IV d. C.

Non se atoparon materiais da época megalítica, unicamente abundantes restos romanos: cerámica común (olas, cuncas, pratos, xarras); terra sigillata hispánica, tanto lisa como decorada; tégulas e ímbrices; vidros e algunhas pezas de ferro.

A situación de Fanegas, así como a de outras mámoas cercanas, relaciónase co camiño román ou vello camiño, que vai polo monte da Corda ata chegar a Cidadela. Este camiño romano discorre preto do Camiño Real, por riba do cal pasa actualmente unha estrada (Bello et al., 1982).

Na serra do Bocelo as mámoas sitúanse en penechairas, en divisorias de augas. Nas zonas de val o número de mámoas é moi inferior, sendo nulo en áreas húmidas, de solos pesados. Está escavada parcialmente a anta de Forno dos Mouros ou da Moruxosa.

O Forno dos Mouros é un impresionante monumento formado por sete chantas graníticas e unha gran lousa de cobertura. Ten corredor alongado de dous tramos. Atopáronse microlitos de sílex e seixo, así como un machado pulimentado, unha maza e un vaso campaniforme do tipo internacional. Na parte interna das chantas existen pinturas que representan liñas paralelas horizontais en zig-zag, en cores vermella e negra.

Os materiais que se utilizaron nas construccións megalíticas da zona foron preferentemente os que conformaban o propio substrato, é dicir, os constructores economizaban o esforzo que requeriría o transporte dende longas distancias, aforrando así enerxía e tempo de traballo.

A maioría das mámoas da serra están aliñadas co Camiño Real que transcorre pola divisoria, e tamén se vinculan a pasos transversais que facilitan a entrada cara ás terras baixas. Pola mesma beira da anta de Forno dos Mouros pasa o Camiño, que está tamén flanqueado por outro túmulo de menor tamaño situado na outra banda.

O emprazamento dos túmulos está claramente relacionado coas vías naturais de tránsito: de xeito especial aparecen túmulos nas cruces, é dicir, nas áreas nas que conflúen zonas de desprazamento lonxitudinal e transversal (Villoch, 1998). 


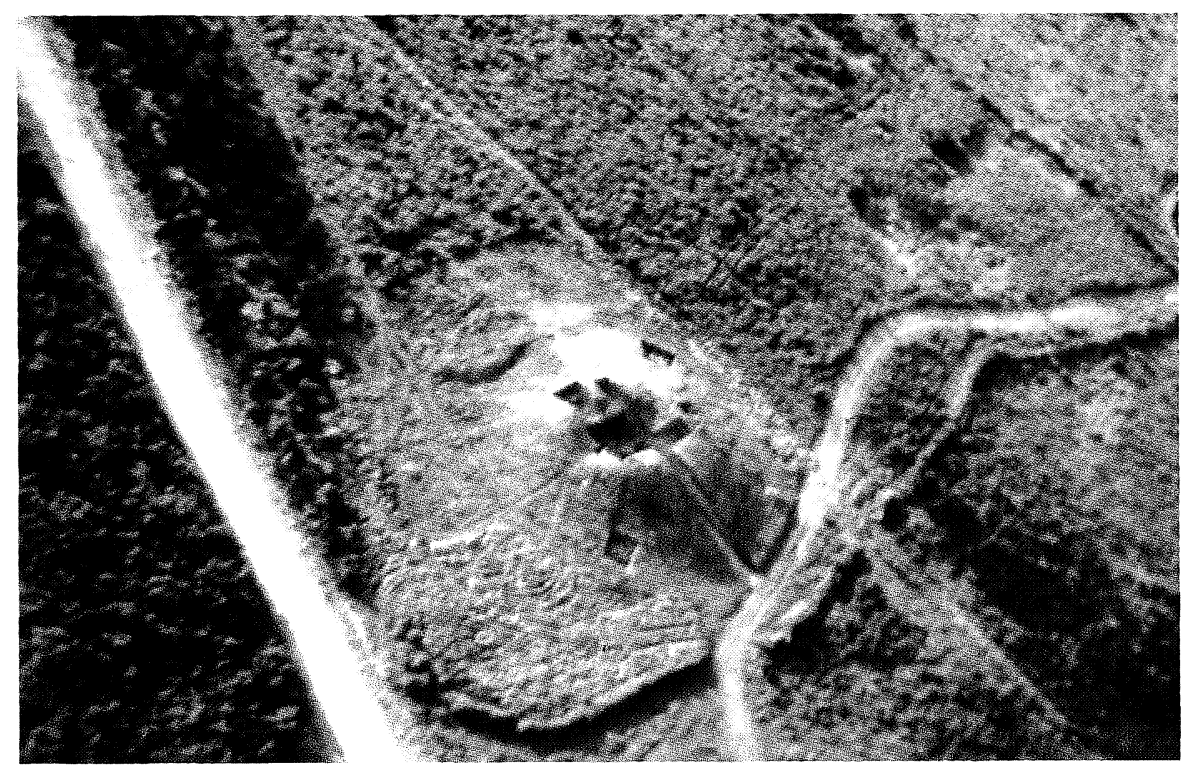

Figura 7.- A medorra de Fanegas e os camiños (Caamaño e Criado, 1991).

\section{OBSERVACIÓNS FINAIS: MÁMOAS EN MOVEMENTO}

As concentracións tumulares responden a unha serie de factores que xa vimos anteriormente: control de vías naturais de paso, visibilidade, condicións do terreo, etc. Un destes factores, cecais dos máis salientables, reside na relación entre as necrópoles e as vías de tránsito. En efecto, tense comprobado que na dorsal meridiana galega (así como noutras zonas de Galicia) as maiores concentracións de túmulos vincúlanse a lugares naturais de paso que comunican zonas altas da serra coas baixas (Eguileta, 1999). Moitas destas claves de tránsito fóronse perpetuando ao longo dos tempos por camiños antigos, Reais e estradas locais, comarcais e nacionais, que en ocasións superpoñíanse unhas ás outras (Criado et al. 1990-91). Os cruces dos camiños máis importantes eran lugares equidistantes dos núcleos de poboación máis numerosa e eran as zonas nas que se celebraban feiras comarcais periodicamente.

Estas vías de tránsito que discorrían polos pasos naturais para acceder a outras zonas sorteando as dificultades orográficas do terreo son utilizadas inda actualmente. Esta circunstancia pode evidenciar a importancia que tiñan no desprazamento das comunidades constructoras de túmulos a facilidade dos accesos: serra-val e viceversa (Vaquero 1993-94). 
Nun estudio sobre a itinerancia dos cabalos que viven en réxime de semiliberdade, amosouse que o emprazamento de túmulos correspondía a zonas polas que transitaban estes animais, polo que os camiños non eran máis que a culturización dunhas vías naturais de tránsito (Infante et al. 1992).

Os camiños perpetúanse no tempo, así temos constancia na Terra de Melide de camiños que se coñecían como vía romana ou tamén camiño francés, polo que é probable que foran utilizados no Medievo polos peregrinos a Compostela (Otero, 1933; Risco, 1933)5. Velaquí outra referencia á perpetuación destas vías, que chegan ata a época contemporánea, ampliándose e causando a destrucción de varias mámoas que estaban situadas a rentes do vello itinerario (López Cuevillas, 1933).

A vinculación das mámoas cos Camiños Reais está demostrada tamén na zona de Vilalba, onde os túmulos alíñanse ao longo dos camiños antigos (Pombo e Vázquez, 1995). É o caso tamén da área megalítica de Pedra Chantada que se sitúa ás beiras do Camiño Real que de Lugo levaba a Ferrol e que actualmente vai paralelo á estrada nacional 641 (Ramil, 1995).

Esta asociación de mámoas a camiños e a perpetuación destes ao longo da historia foi estudiada tamén nalgunha rexión francesa por Germont (cit. Bello et al. 1982), que da por demostrada a reutilización de camiños desde o Neolítico, pasando pola época romana e convertíndose na Idade Media en rutas de peregrinación cara a Compostela.

Camiños prehistóricos, camiños castrexos, vías romanas, rutas medievais, camiños reais, estradas... non son máis ca unha mesma vía de comunicación, inzada de pegadas, que desde hai máis de 5.000 anos permanece protexida polas omnipresentes Antas no Camiño.

\section{BIBLIOGRAFÍA}

ÁLVAREZ, A. (1919). «Mámoas de la época romana». B.R.A.G., n 121. La Coruña.

ÁLVAREZ CARBALLIDO, E. (1890).«Memorándum histórico. La villa de Mellid y su comarca». Galicia Diplomática, año III, $\mathrm{n}^{\circ} 16$. Compostela.

- (1907): «Protohistoria». Boletín de la Real Academia Gallega, año II, n 12. La Coruña.

AMOR MEILÁN, M. (1918). Historia de la provincia de Lugo. Vol. I. Edad Prehistórica. Lugo.

\footnotetext{
${ }^{5}$ Otero Pedrayo da conta das notas de viaxe de J.M. Gil, autor de «Recuerdos de un viaje por Galicia», traballo publicado en 1850 en Compostela na Revista de Galicia. Dise que chegando a Melide existe unha «prominencia circular», que Otero identifica cunha mámoa e que foi «forca feudal».
} 
BARREIRO, B. (1888). «Descubrimientos prehistóricos. Diademas célticas de Mellid». Galicia Diplomática, vol. III, $\mathrm{n}^{\circ} 38$.

BELLO DIÉGUEZ, J.Ma; CRIADO BOADO, F. e VÁZQUEZ VARELA, J.M. (1982). «Sobre la cultura megalítica y los caminos antiguos en Galicia». El Museo de Pontevedra. T. XXXVI; pp. 143-163.

- (1987): La cultura megalítica de la provincia de la Coruña y sus relaciones con el marco natural: Implicaciones socioeconómicas. Excma. Diputación Provincial de La Coruña.

BLAS, M.A. de (1995). «Los episodios prehistóricos recientes en el territorio de los Astures». Astures. Catálogo de la Exposición; pp. 25-39. Gran Enciclopedia Asturiana. Gijón.

BOUZA BREY, F.; CARRO OTERO, J. e G ${ }^{\mathrm{a}}$. MTNEZ. C. (1973). «Excavación de túmulos dolménicos en San Andrés de Lousada (Lugo)». Noticiario Arqueológico Hispano. Prehistoria, 2; pp. 39-55. Madrid.

CAAMAÑO GESTO, J.M. e CRIADO BOADO, F. (1991-92). «La medorra de Fanegas (Sobrado dos Monxes. Coruña). Informe de la campaña de excavación de 1983». Brigantium, 7; pp. 7-89. A Coruña.

CARNEIRO REY, J.A. (1999). «El megalitismo en Galiza: Síntesis cronológica de los estudios territoriales». Estudos Pré-Históricos, 7; pp. 27-36. Centro de Estudos Pré-Históricos da Beira Alta. Viseu.

- (2000). «Toponimia e Arqueoloxía (algunhas notas verbo de toponimia arqueolóxica)». Gallaecia, 19; pp. 369-380. Publicación do Departamento de Historia I. Universidade de Santiago de Compostela.

CARNEIRO REY, J.A. e SERRANO OTERO, J. (2000). «Arqueoloxía e Paisaxe. O Arco Ártabro desde a Prehistoria recente ata o Medievo». Cátedra. Revista Eumesa de Estudios, 7; pp. 119170. Pontedeume.

CASTILLO, A. del (1929). «Un cuchillo de sílex». B.R.A.G., n 216. La Coruña.

CRIADO BOADO, F. (1980). «Catalogación de mámoas en los municipios de Curtis, Sobrado y tierras adyacentes». Brigantium, 1; pp. 13-40. A Coruña.

CRIADO BOADO, F. (Dir. 1991). Arqueología del paisaje. El área Bocelo-Furelos entre los tiempos paleolíticos y medievales. (Campañas de 1987, 1988 y 1989). «Arqueoloxía/Investigación», 6. Xunta de Galicia.

CRIADO BOADO, F. e GRAJAL, M. (1981): «Relación entre la distribución de mámoas y el medio físico en la zona de Sobrado-Curtis». Brigantium, 2; pp. 7-26. A Coruña.

CRIADO BOADO, F.; FÁBREGAS VALCARCE, R. e VAQUERO LASTRES, X. (1990-91). «Concentraciones de túmulos y vías naturales de acceso al interior de Galicia». Portugalia. Nova Série. Vol. XI-XII; pp. 27-38. Instituto de Arqueologia. Faculdade de Letras da Universidade do Porto.

EGUILETA FRANCO, J.Ma. (1999). A Baixa Limia Galega na Prehistoria Recente. Arqueoloxía dunha paisaxe na Galicia interior. Deputación Provincial. Ourense.

FÁBREGAS VALCARCE, R. (1988). «Materiais da mámoa da Martagona». Boletín do Centro de Estudios Melidenses, 4. Melide. 
- (1991). Megalitismo del Noroeste de la Península Ibérica. Tipología y secuencia de los materiales líticos. Aula Abierta, 58. U.N.E.D. Madrid.

- (Ed. 1996). Os primeiros poboadores de Galicia: O Paleolítico. Cadernos do Seminario de Sargadelos, 73. O Castro. Sada. A Coruña.

FÁBREGAS VALCARCE, R. e de la FUENTE ANDRÉS, F. (1988). Aproximaciones a la cultura material del megalitismo gallego: la industria lítica pulimentada y el material cerámico. «Arqueohistórica», 2. Dpto. de Historia I. Universidade de Santiago.

FÁBREGAS VALCARCE, R. e PENEDO ROMERO, R. (1994). «Petroglifos e arte das cistas do Noroeste». Trebaruna, vol. III; pp. 5-21. Castelo-Branco.

INFANTE ROURA, F., VAQUERO LASTRES, J. e CRIADO BOADO, F. (1992). «Vacas, caballos, abrigos y túmulos: definición de una geografía del movimiento para el estudio arqueológico». Cuadernos de Estudios Gallegos. T. XL; fasc. 105; pp. 21-39. Santiago de Compostela.

LEISNER, G. (1938). Verbreitung und Typologie der Galizish-Nordportugiesischen megalithgräber. Marburg.

LEITE DE VASCONCELOS, J. (1905), Religiôes de Lusitania. Vol. I. Lisboa.

LÓPEZ CUEVILLAS, F. (1927). «Papeletas pra un inventario das mámoas galegas». Nós, 40; pp. 9-13. Santiago de Compostela.

- (1933): «Prehistoria de Melide», in Terra de Melide; pp. 31-134. Seminario de Estudos Galegos. Santiago de Compostela.

LÓPEZ CUEVILlAS e BOUZA BREY, F. (1927). «Bibliografía da Prehistoria galega». Nós, 41, 42, 43. Santiago de Compostela.

MACIÑEIRA Y PARDO DE LAMA, F. (1943). «Túmulos prehistóricos. Inventario descriptivo de los 286 túmulos prehistóricos hasta ahora descubiertos en la avanzada comarca del cabo Ortegal». B.R.A.G. T. XXIII; pp. 21-29; 124-134; 178-186. La Coruña.

OTERO PEDRAYO, R. (1933). «A Terra de Melide», in Terra de Melide; pp. 729. S.E.G. Compostela.

POMBO MOSQUERA, X.A. e REGO ÁLVAREZ, Mª.L. (1991-92). «O megalitismo nas terras de Vilalba (Lugo). Addenda». Brigantium, 7; pp. 213-223. A Coruña.

POMBO MOSQUERA, X.A. e VÁZQUEZ VARELA, X.M. (1995). A Prehistoria no Noroeste da Terra Cha. Deputación Provincial. Lugo.

RAMIL REGO, E. (1995): «El área megalítica de Pedra Chantada y su relación con el medio natural». Portugalia. Nova Série. Vol. XVI. Universidade do Porto.

RAMIL, J., VÁZQUEZ VARELA, J.M. e VIDAL, J. (1976). «Tres túmulos megalíticos con grabados en el término municipal de Villalba (Lugo)». Gallaecia, 2; pp. 87-93. Santiago.

RISCO, V. (1933). «Estudio etnográfico da Terra de Melide», in Terra de Melide, pp. 323-424. S.E.G. Compostela.

RODRÍGUEZ CASAL, A.A. (1988). La necrópolis megalítica de Parxubeira. Monografías urxentes do Museu, 4. A Coruña.

- (1990). O Megalitismo. A primeira arquitectura monumental de Galicia. Biblioteca de Divulgación. Serie Galicia, 4. Universidade de Santiago.

Cuadernos de Estudios Gallegos, Tomo LII, Fascículo 118, Santiago 2005. (Págs. 199 - 213) 
- (1993). «Análise historiográfica do megalitismo galego», in J.G. Beramendi (Coord.): Galicia e a Historiografia; pp. 53-71. Compostela.

- (Ed. 1997). O Neolítico Atlántico e as orixes do Megalitismo. Actas do Coloquio Internacional (Santiago, 1996). Universidade de Santiago de Compostela.

SHEE, E. (1975). «L'Art Mégalithique de l'Europe Occidentale», in Actas de las I Jornadas de Metodología Aplicada de las Ciencias Históricas. T. I Prehistoria e Historia Antigua; pp. 101120. Universidade de Santiago de Compostela.

VAQUERO LASTRES, J.L. (1993-94). «Galiñeiro, paso de lobos, novios y héroes. Sobre el emplazamiento de los túmulos del NW». Cuadernos deEstudios Gallegos. T. XLI, fasc. 106; pp. 1139. Santiago.

VÁZQUEZ SEIJAS, M. (1947). «Riqueza megalítica en tierras de Villalba». Boletín de la Comisión de Monumentos Histórico-Artísticos de Lugo. T. II.

VÁZQUEZ VARELA, J.M. e POMBO MOSQUERA, X.A. (1992). «A demografía megalítica no Noroeste da Península Ibérica». Cuadernos deEstudios Gallegos. T. XL; fasc. 105; pp. 7-20. Compostela.

VILASECO VÁZQUEZ, X.I. (1997-98). «Datos sobre a presencia de estructuras de acceso en túmulos megalíticos da provincia de Lugo». Boletín do Museo Provincial de Lugo. T. VIII. Vol 1 ; pp. 125-156.

VILLA-AMIL Y CASTRO, J. (1873). Antigüedades prehistóricas y célticas de Galicia. Lugo. - (1878): «Poblaciones, monumentos y caminos antiguos del norte de la provincia de Lugo». Boletín de la Sociedad Geográfica de Madrid. T. V; pp. 81-139.

VILLOCH VÁZQUEZ, V. (1998). «Paisajes monumentales en un mismo espacio: la Sierra de O Bocelo (Galicia)». Arqueología Espacial 19-20 (Arqueología del Paisaje); pp. 517-528. Teruel.

VV. AA. (1991). Galicia. Historia. T. I: Prehistoria e Historia Antiga. Hércules Ed. A Coruña.

VV. AA. (1993 a). Galicia. Arte. T. IX: Arte Prehistórica e Romana. Hércules De. A Coruña.

VV. AA. (1993 b). La evolución del paisaje en las montañas del entorno de los Caminos Jacobeos. Xunta de Galicia.

VV. AA. (1997). Actas del III Coloquio Internacional de Arte Megalítico. «Brigantium, 10». Boletín do Museo Arqueolóxico e Histórico Castelo de San Antón. A Coruña. 